\title{
Índice de qualidade da água da sub-bacia do Riacho Cacau, Portal da Amazônia
}

\section{Imperatriz- MA}

\author{
The water quality index of the stream Cacau sub-basin, Amazon Portal Imperatriz -MA \\ Índice de calidad sel água de la subcuenca del Arroyo del Cacau, Portal Amazónico Imperatriz-MA
}

Recebido: 03/02/2021 | Revisado: 12/02/2021 | Aceito: 15/02/2021 | Publicado: 23/02/2021

\author{
Marcos Jean Araújo de Sousa \\ ORCID: https://orcid.org/0000-0003-3759-2954 \\ Universidade Federal do Pará, Brasil \\ E-mail: marcosjean.itz@ifma.edu.br \\ Mariane Furtado Gonçalves \\ ORCID: https://orcid.org/0000-0002-2905-1480 \\ Universidade Federal do Pará, Brasil \\ E-mail: marianefg@ufpa.br \\ Jorge Diniz de Oliveira \\ ORCID: https://orcid.org/0000-0001-9421-0524 \\ Universidade Estadual da região Tocantina do Maranhão, Brasil \\ E-mail:jorgediniz@uemasul.edu.br \\ Claudia Karen Silva Lopes \\ ORCID: https://orcid.org/0000-0001-8422-7904 \\ Universidade Estadual da região Tocantina do Maranhão, Brasil \\ E-mail:claudiakaren.bio@gmail.com
}

\begin{abstract}
Resumo
O trabalho teve como objetivo a avaliação da qualidade da água da sub-bacia do Riacho Cacau ao logo dos anos na área urbana da cidade de Imperatriz-MA (portal da Amazônia), visando subsidiar instrumentos de gestão dos recursos hídricos urbanos. Considerou-se neste estudo os aspectos de interferência humana no ecossistema aquático. As interferências na qualidade da água foram avaliadas pelas seguintes variáveis: $\mathrm{pH}$, Potencial redox, Cloretos, Alcalinidade, Acidez, Oxigênio dissolvido, Nitrogênio total, Fósforo total, Temperatura, Condutividade elétrica, Turbidez, sólidos totais, Material particulado em suspensão, Coliformes totais e Coliformes termotolerantes, com os parâmetros criou um banco de dados sobre a real situação do corpo hídrico. Após a avalição das características físico-químicas das águas do riacho foi aplicado o calculado do Índice de Qualidade da Água utilizando o método de Báscaran (IQAb) e o coefiente de correlação Person. O Riacho Cacau obteve índices de qualidade de água variado de bom para excelente nos anos 20152016 quando comparados com os valores 2018-2019, em que 50\% das amostras obtiveram IQA Bom, 25\% IQA Excelente e 25\% Agradável.
\end{abstract}

Palavras-chave: Índice de qualidade; Parâmetros físico-químicos; Água.

\begin{abstract}
The objective of the work was to assess the water quality of the stream Cacau sub-basin over the years in the urban area of the city of Imperatriz-MA (Amazon portal), aiming to subsidize instruments for the management of urban water resources. In this study, aspects of human interference in the aquatic ecosystem were considered. The interferences in the water quality were evaluated by the following variables: $\mathrm{pH}$, Redox potential, Chlorides, Alkalinity, Acidity, Dissolved oxygen, Total nitrogen, Total phosphorus, Temperature, Electrical conductivity, Turbidity, total solids, Particulate matter in suspension, Total and coliforms Thermotolerant coliforms, with the parameters created a database on the real situation of the water body. After assessing the physical and chemical characteristics of the stream waters, the Water Quality Index was calculated using the Basic method (IQAb) and the Person correlation coefficient. Riacho Cacau obtained water quality indexes ranging from good to excellent in the years 2015-2016 when compared to the values 2018-2019, in which $50 \%$ of the samples obtained Good IQA, 25\% Excellent IQA and 25\% Pleasant.
\end{abstract}

Keywords: Quality index; Physico-chemical parameters; Water.

\section{Resumen}

El trabajo tuvo como objetivo evaluar la calidad del agua de la subcuenca del Riacho Cacau a lo largo de los años en el área urbana de la ciudad de Imperatriz-MA (portal da Amazônia), con el objetivo de subsidiar instrumentos para la gestión de los recursos hídricos urbanos. En este estudio se consideraron aspectos de la interferencia humana en el ecosistema acuático. Las interferencias en la calidad del agua se evaluaron mediante las siguientes variables: $\mathrm{pH}$, Potencial redox, Cloruros, Alcalinidad, Acidez, Oxígeno disuelto, Nitrógeno total, Fósforo total, Temperatura, 
Conductividad eléctrica, Turbidez, Sólidos totales, Partículas en suspensión, Totales y coliformes Coliformes termotolerantes, con los parámetros se creó una base de datos sobre la situación real del cuerpo de agua. Luego de evaluar las características físicas y químicas de las aguas de los arroyos, se calculó el Índice de Calidad del Agua utilizando el método Básico (IQAb) y el coeficiente de correlación de Person. Riacho Cacau obtuvo índices de calidad del agua que van de buena a excelente en los años 2015-2016 al compararlos con los valores 2018-2019, en los que el $50 \%$ de las muestras obtuvieron Buen IQA, 25\% Excelente IQA y 25\% Agradable.

Palabras clave: Índice de calidad; Parámetros físico-químicos; Agua.

\section{Introdução}

Ao longo dos anos pode-se observar no Brasil inúmeras mudanças de mentalidade com relação ao uso dos recursos hídricos, isto se dá devido a importância da água para a sobrevivência dos seres vivos. Por isso, medidas de preservação de bacias hidrográficas e da qualidade da água dos corpos hídricos, são necessárias para que ocorra o mínimo de alterações nas características das bacias. As modificações que ocorrem nas características da bacia hidrográfica e que de alguma forma alteram o equilíbrio e a dinâmica dos corpos d'água estão associadas principalmente à poluição existente no território (Poleto, 2014).

A qualidade da água está intimamente ligada às suas características físicas, químicas e biológicas, e sua condição é função dos diferentes usos a que se destina (Abreu \& Cunha, 2015).

Enquanto companhias de saneamento utilizam o IQA para avaliar as condições da água bruta, órgãos de gestão das águas monitoram, de maneira mais ampla, as águas superficiais de sua jurisdição por meio desse indicador (Santos et al., 2018).

Contudo entende-se que a água está ficando cada vez mais escassa por conta da ação do homem nos leitos dos rios, bem como no manejo inadequado de suas nascentes. Fatores como cultura e pouca educação ambiental fazem com que os índices de qualidade da água possam sofrer mudanças, alterando a qualidade da água no consumo humano e na recreação. Assim, faz-se necessário o monitoramento da qualidade da água através de parâmetros físico-químico e microbiológicos, para que possa dar um subsídio maior às políticas dos recursos hídricos e de proteção ambiental.

A avaliação da qualidade da água de mananciais para usos múltiplos assume, nos tempos modernos, grande importância devido ao crescente impacto ambiental negativo que os mesmos vêm sofrendo em função das mais variadas atividades antrópicas.

Com o aumento populacional tem ocorrido a degradação dos recursos hídricos, decorrente principalmente dos usos múltiplos da água na agricultura, pecuária, indústria, geração de energia, saneamento básico e uso de políticas públicas. A avaliação da qualidade da água de mananciais para usos múltiplos assume, nos tempos modernos, grande importância devido ao crescente impacto ambiental negativo que os mesmos vêm sofrendo em função das mais variadas atividades antrópicas.

Para a determinação de impactos ambientais em ecossistemas aquáticos, o estudo das variáveis físico-químicas e biológicas da água permite determinar a situação real do grau de alteração e/ou perturbação da qualidade da água submetida as mais diversas fontes de poluição (Silva \& Jardim, 2007).

Assim, o presente estudo tem como objetivo realizar uma análise sobre o índice de qualidade da água da sub-bacia do Riacho Cacau, afluente do rio Tocantins, área urbana da cidade de Imperatriz-MA.

\section{Metodologia}

\section{1 Área de Estudo}

A sub-bacia corpo hídrico investigado está localizado na Mesorregião Oeste do Maranhão ao longo do perímetro 
urbano da cidade de Imperatriz o qual desagua no Rio Tocantins, a sub-bacia do Cacau encontra-se entre as coordenadas geográficas: $47^{\circ} 05^{\prime}$ a $47^{\circ} 25^{\prime}$ Long. W e $5^{\circ} 00^{\prime}$ a $5^{\circ} 40^{\prime}$ Lat.S. Os pontos investigados estão localizados ao longo do perímetro urbano da cidade de Imperatriz (Figura 1).

Figura 1 - Mapa dos pontos amostrais na Bacia do Riacho Cacau.

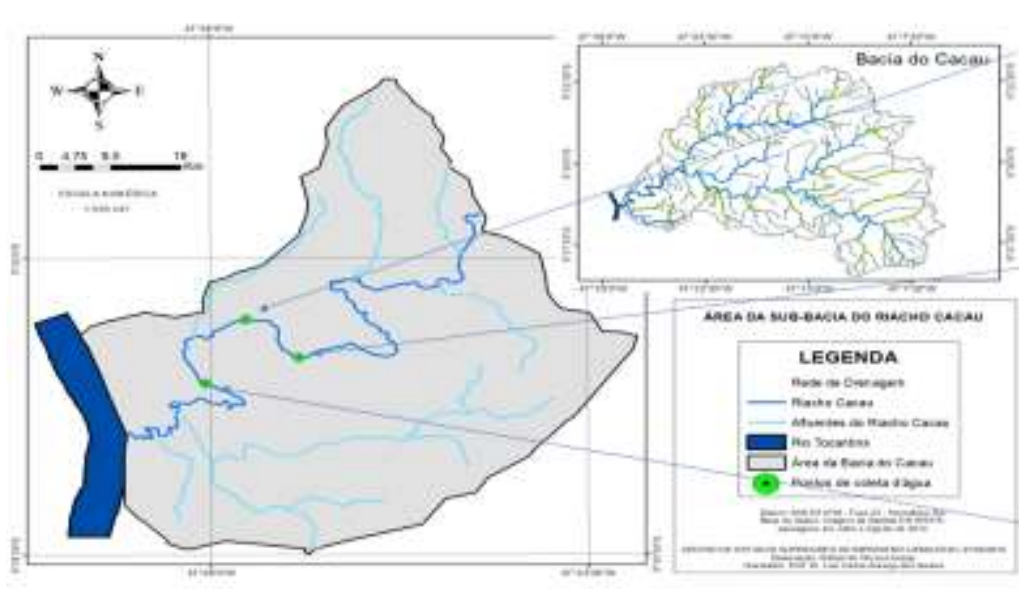

\author{
Rua Antônio Pereira \\ Bairro: Parque \\ Alvorada I \\ Ponto 1 \\ Avenida Atlantica \\ Bairro: Vilinha \\ Ponto 2 \\ Avenida da liberdade \\ Bairro: Parque \\ Anhanguera \\ Ponto 3
}

Fonte: Araújo \& Sousa (2018).

\title{
2.2 Coleta e Análises das Amostras de Água
}

Após definido o Riacho Cacau como objeto de estudo, foi realizada a etapa do planejamento de coleta de água. Para isso foi verificada a disponibilidade de transporte até o local de coleta, bem como a organização do material em campo até a chegada no laboratório.

Nesta etapa do trabalho focou-se na execução das coletas, na realização de análises in loco e na preservação e transporte de amostras para o laboratório, buscando-se informações sobre uso da água e sobre atividades associadas aos usos múltiplos na área estudada.

Para determinação estatística, utilizou-se o coeficiente de Pearson (r) na correlação entre os parâmetros de qualidade de água. Os resultados das amostras coletadas foram inseridos em planilhas do Excel®, no qual foi realizado o cálculo do IQA, e as análises de correlação foram feitas no software Statistic ${ }^{\circledR}$, desenvolvido pela "StatSoft".

Após testar a homogeneidade de variância, foi realizada a correlação de Pearson, o r e o p estatístico para cada uma das análises. A interpretação para cada correlação é simples e direta. Valores de R negativo indicam correlação negativa, a linha da regressão será decrescente. Significa que quando um parâmetro físico-químico aumenta o outro diminui. Por outro, lado, valores de R positivo indicam correlação positiva, a linha de regressão nesse caso será crescente. Significa que ambos os parâmetros testados estão correlacionados positivamente. Significa que quando um parâmetro físico-químico aumenta o outro também aumenta. Utilize essa forma para interpretar cada um dos gráficos.

Foram realizadas duas coletas de água no Riacho do Cacau, nos anos de dezembro de 2015 e julho de 2016 , no período chuvoso e não chuvoso. No período de 2018 e 2019, foram realizadas 2 coletas, também no período não chuvoso e outra no período chuvoso. As coletas foram realizadas nos dias 12 de dezembro de 2018 e 05 de julho de 2019.

Nas amostras de água foram realizadas análises físico-químicas e biológicas, mostradas e descritas nos itens subsequentes: 
- pH, Potencial redox -ORP, Cloretos, Alcalinidade, Acidez, Oxigênio Dissolvido, Nitrogênio Total e Fósforo Total;

- Temperatura, Condutividade Elétrica -CE, Turbidez, Sólidos Totais e Material Particulado em Suspensão;

- Coliformes Totais e Coliformes Termotolerantes.

\subsubsection{Análise das Variáveis Químicas}

Nas medidas do potencial redox foi utilizado pHmetro de bancada modelo $\mathrm{pH}-21 \mathrm{pH} / \mathrm{mV}$ meter da HANNA, calibrado com uma solução tampão no pH 4,0 e pH 7,0. Na determinação dessas variáveis o eletrodo entrou em contato direto com a mostra de água (Macêdo, 2001).

$\mathrm{Na}$ determinação de cloreto foram utilizados $50 \mathrm{~mL}$ da amostra, em seguida foi adicionado $1 \mathrm{ml}$ da solução H2O2 e deixado sob agitação por 1 minuto. É importante lembrar que na titulação em presença do indicador cromato a amostra deve estar inicialmente na faixa de $\mathrm{pH}$ de 7.0 a 10.0. Foram adicionados $0,5 \mathrm{~mL}$ de cromato de potássio e titulada com solução de nitrato de prata $0,02 \mathrm{~N}$ até aparecimento da primeira coloração avermelhada o volume gasto foi anotado (VA) (Macêdo, 2001).

A determinação da alcalinidade total foi realizada por intermédio do método volumétrico com detecção potenciométrica foi utilizado pHmetro de bancada modelo $\mathrm{pH}-21 \mathrm{pH} / \mathrm{mV}$ meter da HANNA com eletrodo de vidros. Uma alíquota de $50 \mathrm{ml}$ da amostra homogeneizada foi transferida para um Becker de $100 \mathrm{ml}$, na amostra foi introduzido um eletrodo de vidro previamente calibrado em $\mathrm{pH} 4,0$ e pH 7,0. A titulação foi realizada até o $\mathrm{pH}$ final de 4,5 o volume gasto foi anotado. A determinação da alcalinidade total e parcial foram realizadas de acordo com Macêdo (2001).

Com o auxílio de uma pipeta volumétrica foi transferido $50 \mathrm{~mL}$ da amostra homogeneizada para um erlenmayer de $250 \mathrm{~mL}$. Foi adicionado aproximadamente 2 gotas de fenolftaleína. Em seguida a amostra foi titulada com uma solução de hidróxido de sódio 1 mol L-1 padronizada com agitação constante, o volume gasto foi anotado e utilizado na determinação da acidez de acordo com equação proposta por Macêdo (2001).

A determinação de nitrogênio foi realizando por meio do método Kjeldahl, onde a amostra é digerida com ácido sulfúrico concentrado sob aquecimento, transformando todo o nitrogênio orgânico em íons amônio. Na etapa subsequente a solução obtida é alcalinizada com hidróxido de sódio concentrado e a amônia produzida nessa etapa é destilada e captada por uma solução de ácido bórico, que então é titulada com ácido padronizado (Vieira, et. al, 2016).

Para a determinação de Fósforo total, $100 \mathrm{~mL}$ da amostra preservada e sem filtrar foi digerida sob aquecimento, em meio ácido, com $15 \mathrm{~mL}$ de solução de Persulfato de Potássio e, em seguida, procedeu se a concentração da amostra até em torno de $15 \mathrm{~mL}$, posteriormente, neutralizou e avolumou quantitativamente a $25 \mathrm{~mL}$. O Fósforo (P) no extrato foi determinado em espectrofotômetro (CETESB, 1978).

\subsubsection{Análise das Variáveis Físicas}

As determinações da turbidez foram realizadas utilizando um Turbidímetro microprocessador de bancada da Tecnopon modelo TB -1000 da ADAMO. As amostras após agitação e desaparecimento das bolhas de ar foram coladas em tubo de vidro apropriado para a leitura em turbidímetro, que em seguida foi inserido na câmara do turbidímetro previamente calibrado e permaneceu até que a leitura estabilizou (Macêdo, 2001).

Os sólidos totais foram determinados pelo método gravimétrico, em um erlenmeyer $250 \mathrm{~mL}$ seco a $100^{\circ} \mathrm{C}$, e aferido foram adicionados $50 \mathrm{~mL}$ da amostra, em seguida a amostra foi submetida a evaporação em capela a $100^{\circ}$ C. Após a evaporação as amostras foram transferidas para uma estufa e foram submetidas a aquecimento a $100^{\circ} \mathrm{C}$ por $24^{\circ}$ decorrido o tempo de secagem as mostras foram resfriadas em dessecador e pesadas. A concentração de sólidos totais foi determinada por 
diferença de peso (Macêdo, 2001).

Para a determinação do Material Particulado em Suspensão uma alíquota de $1 \mathrm{~L}$ das águas não acidificadas para análise de material particulado em suspensão e metais dissolvidos foram imediatamente filtradas com auxílio de uma bomba de vácuo em filtro de membrana $0,45 \mu \mathrm{m}$, previamente seca a $60^{\circ} \mathrm{C}$ e pesada. Após a filtração, o material particulado (resíduo na membrana) foi seco em estufa $60 \square 5^{\circ} \mathrm{C}$, por aproximadamente 24 horas, e resfriado em dessecador. A concentração final do material particulado em suspensão (MPS), que constitui a fração orgânica e inorgânica do MPS, foi obtida por diferença de peso das membranas antes e após a filtração (Jordão et al., 1999; Oliveira, 2006).

\subsection{Análise das Variáveis Biológicas}

Para determinação dos Coliformes Totais foi utilizada uma bateria contendo 15 tubos de ensaio distribuídos de 5 em 5; nos primeiros 5 tubos, (os que contêm caldo lactosado de concentração dupla) inocular, com pipeta esterilizada, $10 \mathrm{~mL}$ da amostra de água a ser examinada, em cada tubo. (Diluição 1:1); nos 10 tubos restantes, apões inocular nos 5 primeiros $1 \mathrm{~mL}$ da amostra (Diluição 1:10) e nos 5 últimos tubos, inocular 0,1 mL da amostra, em cada tubo. (Diluição 1:100); misturar; e incubar a $35 \pm 0,5$ oC durante 24/48 horas; se no final de 24/48 horas, houver a formação de gás dentro do tubo de Durhan, significa que o teste presuntivo foi positivo. Neste caso, é feito o teste confirmativo. Se não houver a formação de gás durante o período de incubação, o exame termina nessa fase e o resultado do teste é considerado negativo.

Para determinação de Coliformes Termotolerantes na primeira etapa, foram retirados assepticamente $25 \mathrm{~mL}$ de amostra e preparadas três diluições sucessivas $(0,1 ; 0,01$ e 0,001$)$ e para cada diluição foram utilizados três tubos contendo 10 $\mathrm{mL}$ de Caldo Lauril Sulfato de Sódio (LST) com tubos de Durhan invertidos, os quais foram posteriormente incubados de 35 a $37^{\circ} \mathrm{C}$ por 24 horas. Os tubos que apresentaram formação de gás no Caldo LST, tiveram alíquotas semeadas em tubos contendo $5 \mathrm{~mL}$ de Caldo verde brilhante 2\% (VB) contendo tubos de Durhan invertidos para o crescimento de coliformes totais. Em uma segunda etapa, os tubos positivos para VB Determinação quantitativa pela técnica de tubos múltiplos foram transferidos para tubos contendo caldo com Escherichia coli (E.C.), meio confirmatório para coliformes termotolerantes (E.C.) e deixados em banho-maria de 44,5 a $45^{\circ} \mathrm{C}$ durante 24 horas.

\subsection{Análise da Água Realizadas no Local de Coleta}

Nos locais de coleta das amostras de água superficiais do Riacho Cacau foram determinados alguns parâmetros como: temperatura, pH, Oxigênio Dissolvido (OD) e Condutividade Elétrica (CE). Para isso, foi utilizado o medidor de Multiparâmetro da Água portátil modeloSX751 Marca SAXIN, todas as amostras foram coletas na superfície do corpo hídrico em triplicata.

Após a coleta as amostras de água foram transportadas em recipientes termicamente isolados sob resfriamento e no laboratório foram analisados os parâmetros cloretos, alcalinidade, acidez, turbidez, material particulado em suspensão e sólidos totais em seguida foram realizadas as determinações de nitrogênio total, fósforo total, coliformes totais e coliformes termotolerantes.

\subsection{Determinação de Correlação}

O coeficiente de correlação de Pearson (Equação 1) varia entre -1 e 1, o sinal negativo e positivo indica a direção e o valor da magnitude da correlação, se o valor obtido estiver próximo de 1, mais forte é o nível de associação das variáveis, mas se o valor estiver próximo de 0 menor é o nível de associação. Quando a correlação é positiva, os parâmetros analisados são 
proporcionais e quando negativa os parâmetros são inversamente proporcionais, ou seja, a obtenção de uma correlação positiva indica que quando um parâmetro aumenta o outro também aumenta e, a correlação negativa indica que quando um parâmetro aumenta o outro diminui (Figueiredo \& Silva, 2008).

$$
r=\frac{1}{n-1} \sum\left(\frac{x_{i-\bar{x}}}{S_{x}}\right)\left(\frac{y_{i-\bar{Y}}}{S_{y}}\right.
$$

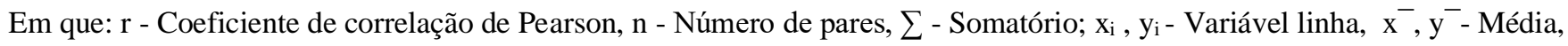
$\mathrm{S}_{\mathrm{x}}$ e $\mathrm{S}_{\mathrm{y}}$ - Desvio Padrão.

\subsection{Metodologia de IQA}

Neste trabalho foi utilizando o Índice de Qualidade de Água de Bascarán (IQAb), pois diferente de outros índices é bastante flexível, pois permite a introdução ou exclusão de variáveis de acordo com as necessidades ou limitações para obtenção de dados, sendo possível definir um índice básico com um número reduzido de variáveis e outro completo com maior número de variáveis (Rizzi, 2001).A partir das variáveis analisadas calculou-se a média dos resultados de cada parâmetro e pode-se determinar o Índice de Qualidade da Água de Báscaran- IQAb. Assim, o IQAb foi calculado utilizando-se a equação 2.

$$
\mathrm{IQAb}=\mathrm{K} \times\left(\sum \mathrm{Ci} \times \mathrm{Pi}\right) / \sum \mathrm{Pi} \quad \text { Equação } 2 .
$$

Em que: $\mathrm{Ci}$ é o valor percentual correspondente à variável (tabelado), Pi é o peso correspondente a cada variável (tabelado), K é a constante de ajuste em função do aspecto visual das águas (1,00 para águas claras; 0,75 para águas com ligeira cor, espuma e turbidez; 0,50 para águas contaminadas e com forte odor; 0,25 para águas que apresentam fermentações e odores).

O valor de IQAb varia de 0 a 100 e corresponde a uma escala qualitativa de caracterização que varia desde o aspecto péssimo ao excelente (Tabela 1$)$.

Nessa pesquisa foram utilizados dados da precipitação fornecido pelo Instituto Nacional de Meteorologia (INMET), com base nos valores fornecidos pelo INMET foi possível dividir precisamente os períodos do ano em chuvoso e não chuvoso, nota-se que os anos de 2015 e 2016 tiveram um nível menor de precipitação no período chuvoso em relação aos demais anos. Sendo assim é possível inferir que quanto maior a precipitação em uma determinada região menor serão os valores detectados nos corpos hídricos daquela região. O que justifica os valores menores nos anos de 2018 e 2019 visto que em relação aos anos de 2015 e 2016 os mesmos tiveram um nível elevando de precipitação.

Tabela 1 - Aspecto aparente de qualidade da água em função do valor de IQAb calculado.

\begin{tabular}{lclc}
\hline \multicolumn{1}{c}{ Aspectos aparente } & Valor de IQAb & Aspecto aparente & Valor de IQAb \\
\hline Péssimo & 0 & Aceitável & 60 \\
\hline Muito ruim & 10 & Agradável & 70 \\
\hline Ruim & 20 & Bom & 80 \\
\hline Desagradável & 30 & Muito Bom & 90 \\
\hline Improprio & 40 & Excelente & 100 \\
\hline Normal & 50 & & \\
\hline
\end{tabular}

Fonte: Coradi et al. (2009). 


\section{Resultados e Discursão}

Para avaliar a qualidade da água do Riacho Cacau, foram utilizadas as análises físico-químicas normatizadas pela Resolução CONAMA 357/2005. Nessa pesquisa foram analisadas as seguintes variáveis mostradas nos itens subsequentes.

\subsection{Variáveis Químicas}

$\mathrm{O}$ pH é um parâmetro importante na avaliação de um corpo hídrico, pois este está diretamente relacionado com a disponibilidade de nutrientes para as plantas, influenciando várias reações definindo mecanismos de sorção e alterando o equilíbrio químico (Jordão et al., 1999). Tais valores foram investigados nos períodos chuvoso e não chuvoso no corpo hídrico no riacho cacau em imperatriz -Ma.

Tundis (2008), afirma que, o potencial redox (ORP) representa alterações no estado de oxidação de muitos íons ou nutrientes e está relacionado à solubilidade de metais e à disponibilidade de nutrientes para as comunidades aquáticas. Valores positivos de ORP indicam condições oxidantes, enquanto que valores negativos indicam disponibilidade de elétrons, ou condições redutoras. Os resultados encontrados para ORP nas águas no Riacho Cacau em todos os pontos no período chuvoso apresentaram valores positivos para ORP indicam condições oxidantes com um aumento significativo no ano de $2019 \mathrm{em}$ relação a 2015 com base nos dados da precipitação do município de Imperatriz, pode-se inferir esse comportamento é decorrente do maior volume hídrico no ano em questão causado pelas fortes chuvas que provocaram o efeito de diluição.

A Resolução CONAMA 357/05 não estabelece padrões para o ORP. Entretanto, para o Ministério do Meio Ambiente citado por Fiorucci e Benedetti Filho (2005), valores de ORP entre $200 \mathrm{mV}$ e $600 \mathrm{mV}$ indicam um meio fortemente oxidante, entre $-100 \mathrm{mV}$ e -200 mV indicam meios redutores e as condições de um rio não poluído são fracamente oxidantes graças à presença de quantidades limitadas de oxigênio dissolvido.

Os valores obtidos para o $\mathrm{pH}$ encontram-se dentro da faixa considerada para manutenção da vida aquática pela legislação brasileira (CONAMA 357/05) a qual estabelece valores variado entre 6 e 9, o pH do Riacho Cacau permanece dentro dos valores preconizados pela resolução CONAMA. Quando observando os valores mais recentes do $\mathrm{pH}$ verifica-se que ponto 3 apresentou o mesmo comportamento ligeiramente ácido da pesquisa anterior (Figura 2).

Os resultados encontrados para ORP nas águas no Riacho Cacau em todos os pontos no período chuvoso apresentam valores positivos para ORP, indicando condições oxidantes com um aumento significativo no ano de 2019 em relação a 2015 com base nos dados da Precipitação do município de Imperatriz pode-se inferir esse comportamento é decorrente do maior volume hídrico no ano em questão causado pelas fortes chuvas que provocarão o efeito de diluição. 
Figura 2 - Variação do pH e de Potencial Redox (ORP).

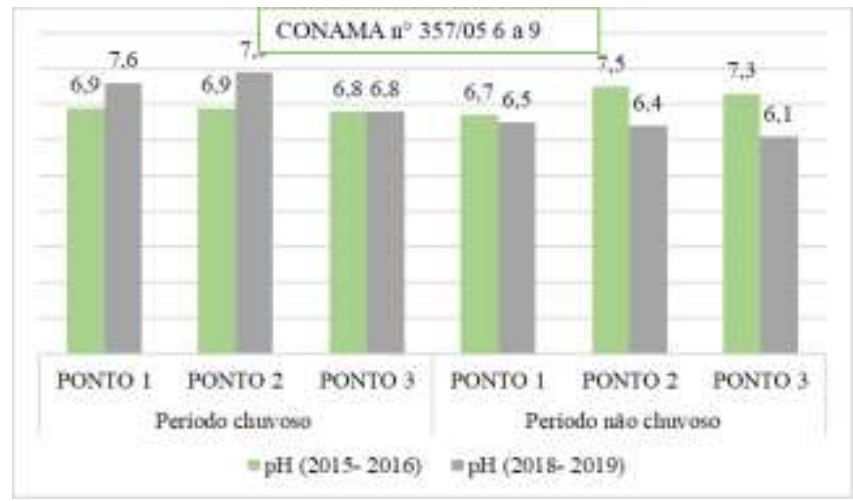

(a) Variação de $\mathrm{pH}$

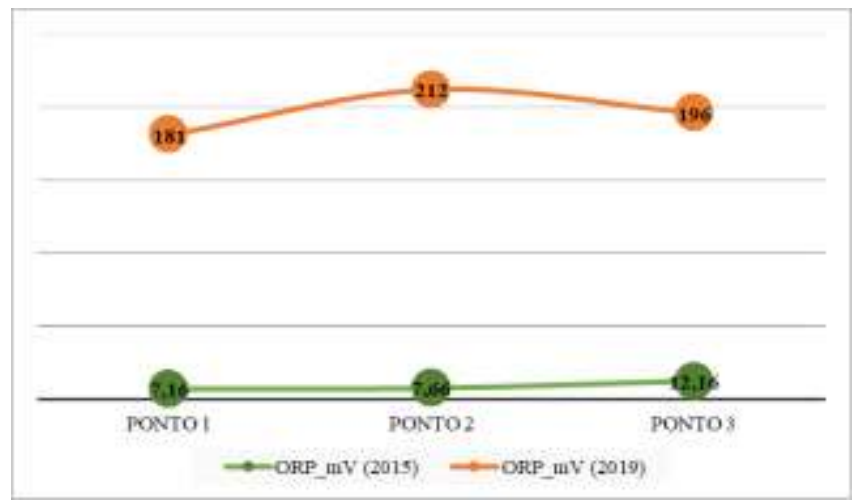

(b) Potencial Redox (ORP)

Fonte: Autores (2021).

A presença de cloretos em corpos hídricos pode ser resultante das dissoluções de sais da intrusão de águas salinas ou por lançamento de despejo de efluentes domésticos e indústrias (Libânio, 2005). Nas águas superficiais são fontes importantes de cloreto as descargas de esgotos sanitários, visto que cada pessoa expele através da urina cerca 6 g de cloreto por dia, o que faz com que os esgotos apresentem concentrações que podem ultrapassar a $15 \mathrm{mg}$ L-1. (CETESB, 2008).

Os valores médios aferidos no Riacho Cacau de modo geral apresentaram as menores concentrações de cloretos nos dados mais recentes, esses resultados estão relacionados com o nível de vazão hídrica dos anos em questão. Macêdo (2001) afirma que cloretos são encontrados em águas naturais em níveis baixos (7,5 mgL-1) e Tucci (2001) confirma que concentrações elevadas de cloreto não são desejáveis em águas de classe 2. Nota-se, na Figura 3, que ambos os valores se encontram em níveis bem inferiores aos máximos permitidos pela Resolução $\mathrm{N}^{\circ} 357 / 05$ do CONAMA onde os valores máximos são de até 250 (mgL-1).

Os valores médios aferidos no Riacho Cacau de modo geral apresentaram as menores concentrações de cloretos nos dados mais recentes, esses resultados estão relacionados com o nível de vazão hídrica dos anos em questão.

Figura 3 - Valores de Cloretos.

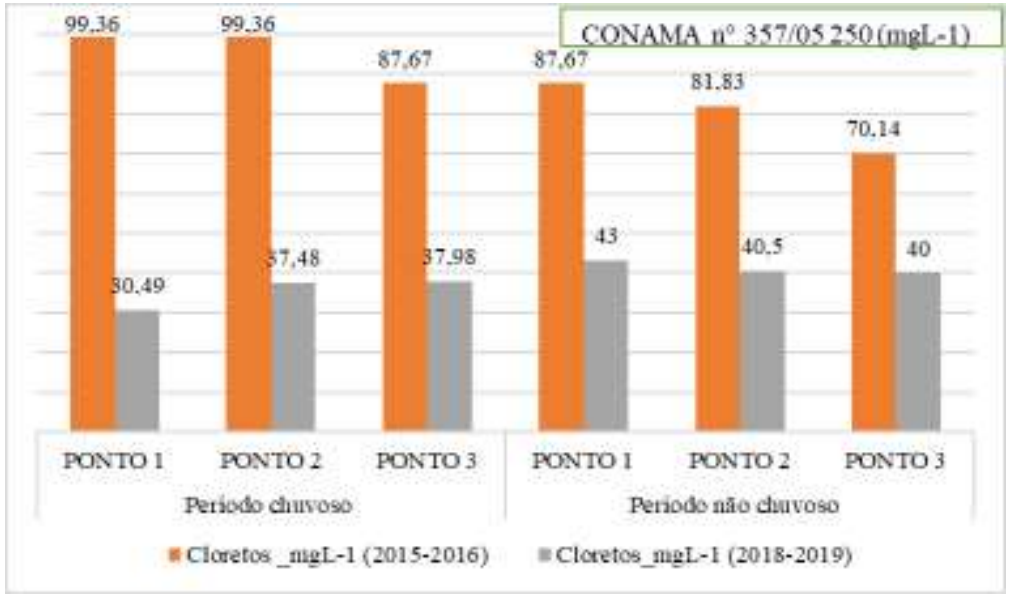

Fonte: Autores (2021).

A alcalinidade de uma água é a medida da sua capacidade de neutralizar ácidos ou absorver íons de hidrogênio sem 
mudança significativa do $\mathrm{pH}$. As principais fontes de alcalinidade em águas ocorrem na presença de bicarbonatos produzidos pela ação do gás carbônico dissolvido na água sobre rochas calcárias. Nos pontos 2 e 3 do Riacho Cacau houve valores da mesma magnitude no período não chuvoso e 1 e 2 no período chuvoso na pesquisa anterior enquanto que na pesquisa mais recente não foi detectada alcalinidade para os 3 pontos no período chuvoso esse comportamento ponde ser decorrente do efeito de diluição devido ao maior acumulo hídrico provocado pelas fortes chuvas (Figura 4a).

Quando há pouca matéria orgânica a decomposição microbiana não ocorre ou reduz diminuído relativamente a quantidade de $\mathrm{CO} 2$ no corpo hídrico, quando o gás carbono se combina com sais ocorre a formação de bicarbonatos formado uma solução tampão aumentando a eficiência desta solução em manter os valores do pH de uma solução. A acidez do Riacho Cacau apresentou valores da mesma magnitude nos dois anos estudados, sendo que quando comparados os valores de anteriores com os valores de mais recentes nota-se uma diminuição da acidez para todos os pontos esse corpo hídrico (Figura 4b).

Figura 4 - Valores de Alcalinidade e Acidez em ambos os períodos dos anos estudado.

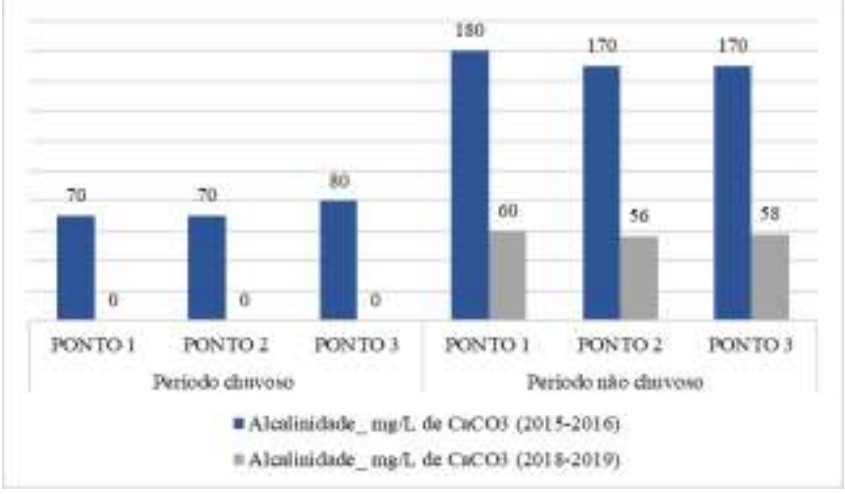

(a) Alcalinidade

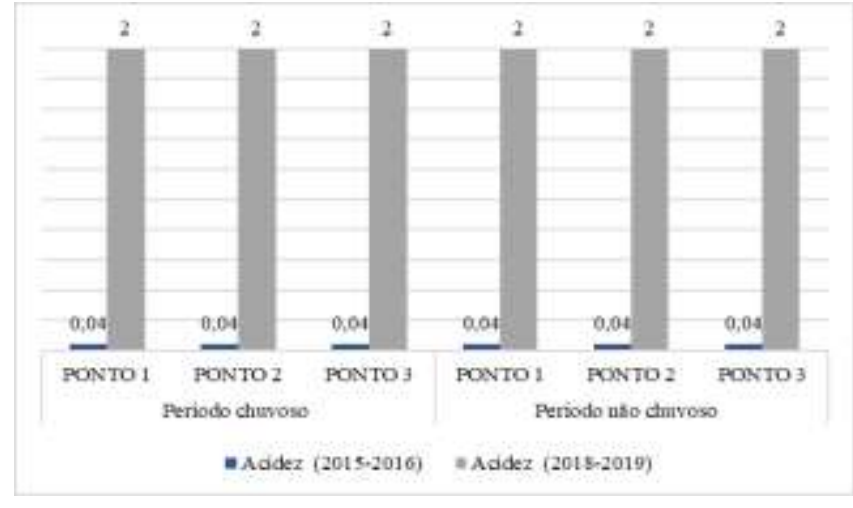

(b) Acidez

Fonte: Autores (2021).

O oxigênio dissolvido (OD) é um importante parâmetro, fundamental para a autodepuração dos rios, com aumento da poluição diminui-se a disponibilidade de oxigênio dissolvido que é consumido pela matéria orgânica em decomposição e prejudica a qualidade da vida aquática (Sperling, 2005). Avaliar a presença de oxigênio dissolvido nas águas de bacias hidrográficas, resulta no conhecimento do grau de arejamento da água, sendo de extrema importância para compreender sua qualidade. Observa-se na Figura 5, com exceção do ponto 3 no período não chuvoso os valores do oxigênio dissolvido não ultrapassaram o valor recomendado pela Resolução CONAMA de $n^{\circ}$ 357/2005 que estabelece que o valor do oxigênio dissolvido não deve ser inferior a: $4 \mathrm{mg} / \mathrm{L}$. As águas limpas possuem teor de oxigênio dissolvido superior a $5 \mathrm{mg} / \mathrm{L}$, exceto se houverem condições naturais que promovam valores menores para esse parâmetro (Brasil, 2005). 
Figura 5 - Oxigênio Dissolvido em ambos os períodos dos anos de 2018 e 2019.

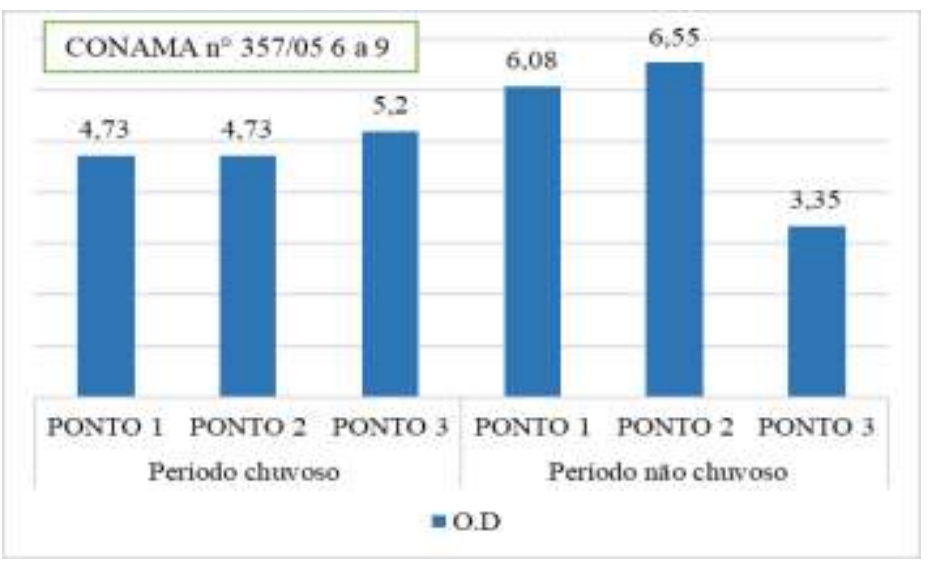

Fonte: Autores (2021).

A presença de grande quantidade de nutrientes como nitrogênio e fósforo nos efluentes leva ao desenvolvimento em excesso de algas e por consequência tem-se a eutrofização de rios, riachos, lagos e lagoas (Braga et al., 2005).

Quanto à concentração de fósforo total para a classe 2, a resolução CONAMA nº 357/2005 indica como limite máximo $0,1 \mathrm{mg} \mathrm{L-1}$. Com base nos valores dessa pesquisa nota-se que no período não chuvoso os valores ultrapassaram o determinando pela resolução CONAMA nº 357/2005 com o dobro do limite máximo 0,1 mg L-1 (Figura 6).

Figura 6 - Valores de Nitrogênio e Fósforo Total em ambos os períodos dos anos de 2018 e 2019.

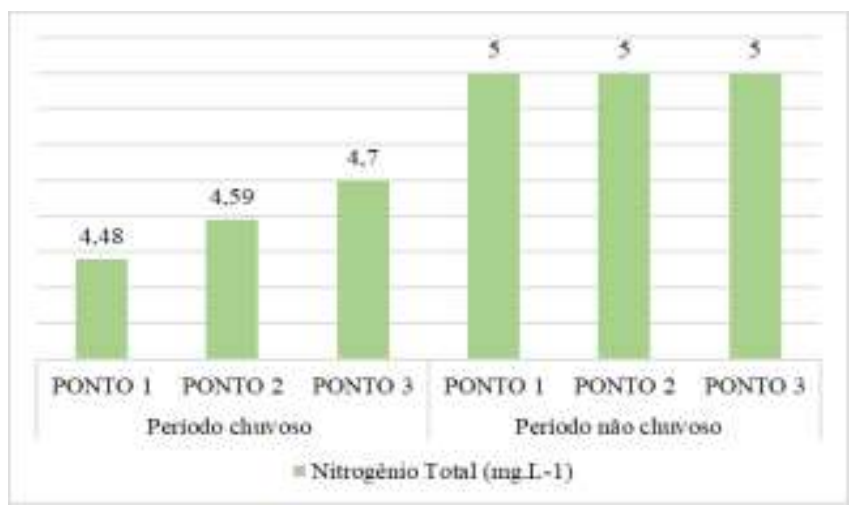

(a) Nitrogênio Total

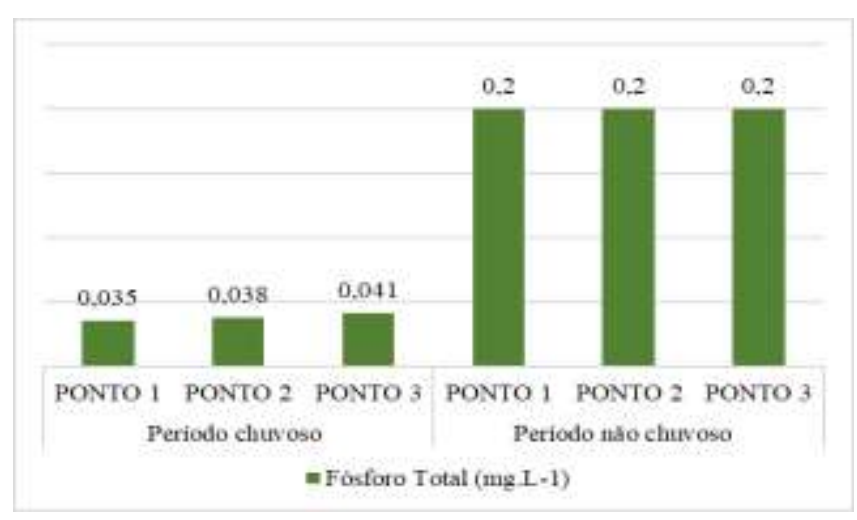

(b) Fósforo Total

Fonte: Autores (2021).

\subsection{Variáveis Físicas}

As temperaturas encontradas para o Riacho Cacau apresentaram variação ao logo do perímetro investigado de 29,71 a 29,73 no período não chuvoso e no período chuvoso 27,75 a 27,76 no ano de 2015 quando comparados os resultados anteriores com os resultados mais atuais nota-se que ocorreu um aumento da temperatura nos pontos 2 e 3 no período chuvoso e uma diminuição de todos os pontos no período não chuvoso esses resultados podem estar relacionados com o horário da coleta (Figura 7a).

No Riacho Cacau foram observados os maiores valores para a condutividade no período não chuvoso e os menores no período chuvoso no ano de 2015 onde as variações na condutividade foram de 201,59 a 361,65 $\mu \mathrm{mS} \mathrm{cm-1} \mathrm{para} \mathrm{o} \mathrm{Cacau} \mathrm{,}$ quando comparamos esses resultados com os obtidos nesta pesquisa observa-se que, mesmo com um maior acumulo hídrico 
em 2018 e 2019 ocorreu um aumento para a condutividade nos pontos 1 e 2 as diferenças entre os resultados podem ser explicadas pelo aumento de efluentes domésticos ao longo dos anos do Riacho Cacau, em virtude, do crescimento imobiliário na cidade de Imperatriz nas proximidades desse corpo hídrico (Figura 7b).

Segundo Paláez-Rodrigues et al. (2002), os valores de C.E, para as águas ao logo das duas pesquisas demostra que o ecossistema aquático investigado possui uma C.E acima da faixa considerada para água de ambiente lótico não contaminado, entre 6 a $30 \mu \mathrm{S}$ cm-1.

Figura 7 - Valores da Temperatura e Condutividade Elétrica.

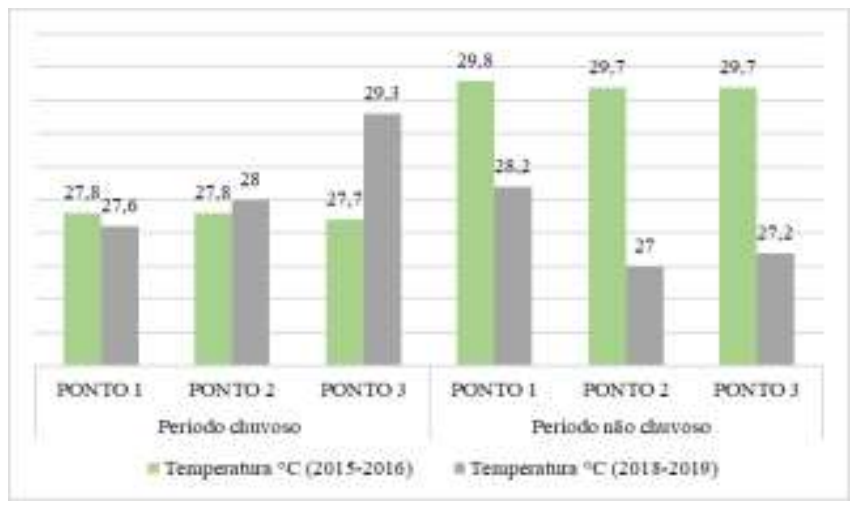

(a) Temperatura

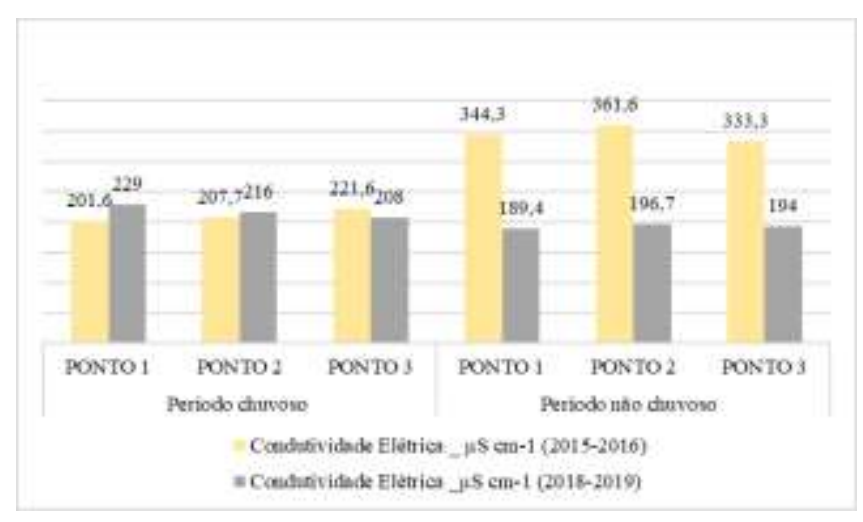

(b) Condutividade Elétrica (CE)

Fonte: Autores (2021).

A turbidez influencia as comunidades biológicas aquáticas e afeta adversamente o uso doméstico, industrial e recreativo (Gertel, et al., 2003). Pode-se observar na Figura 8a, quando comparados os resultados de turbidez mais atuais com os resultados anteriores notasse que com exceção dos pontos 1 e 2 no período chuvoso o Riacho Cacau apresentou uma diminuição da sua turbidez provavelmente devido o efeito de diluição de detritos orgânicos no período estudado. Os resultados obtidos estão abaixo de 100 NTU, que é o limite máximo permitido segundo a Resolução CONAMA n³57/2005 para rio de Classe 2.

Os valores de sólidos totais obtidos refletem a condição do local com aumento em locais de maior poluição, as concertações de sólidos totais não ultrapassaram o valor preconizado pela resolução CONAMA 357/05 nos períodos investigados para corpos hídricos de classe 1, 2 e 3 (500 mg mL-1) com uma diminuição nos valores mais recente quando comparada com os dados dos anos anteriores, esses resultados estão relacionados com o maior nível na vazão hídrica no período das coletas, decorrentes das fortes chuvas que ocorreram nos últimos dois anos (Figura 8b).

A concentrações de material particulado em suspensão em águas superficiais variam em de 5 a 50 mg L-1. Na Figura $8 \mathrm{c}$ nota-se que com exceção do ponto 3 nos dois períodos investigados todos os valores estiveram acima dos valores detectados anteriormente, sendo que no período não chuvoso com exceção do ponto 1 da pesquisa anterior. Esse comportamento pode ser atribuído ao assoreamento provocado pelas fortes chuvas que ocorreram nas proximidades dos pontos de amostragem. 
Figura 8 - Valores de Turbidez, Sólidos Totais e Material Particulado em Suspensão.

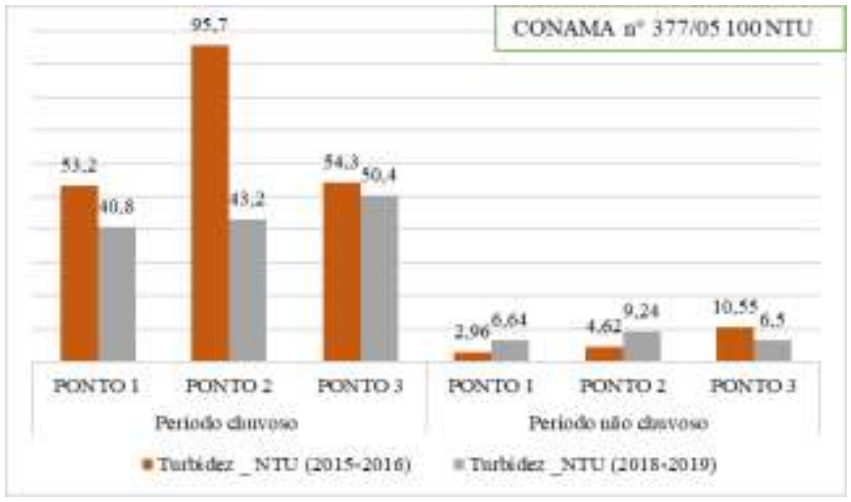

(a) Turbidez

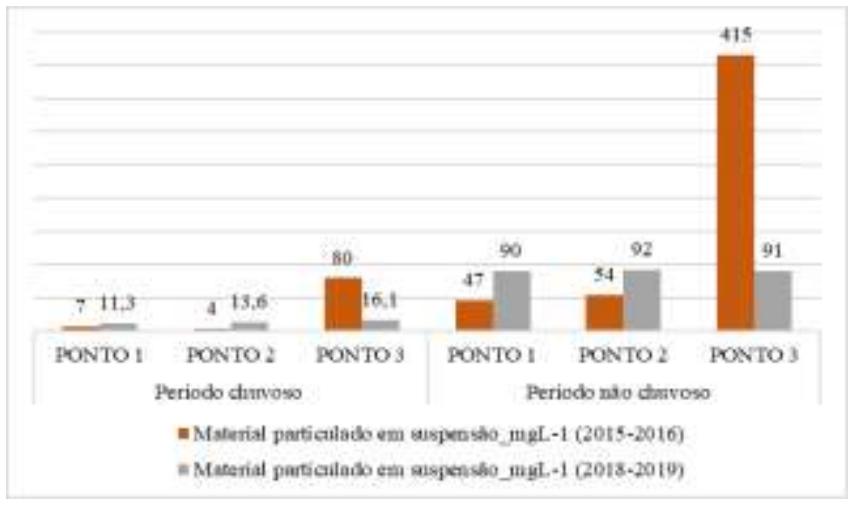

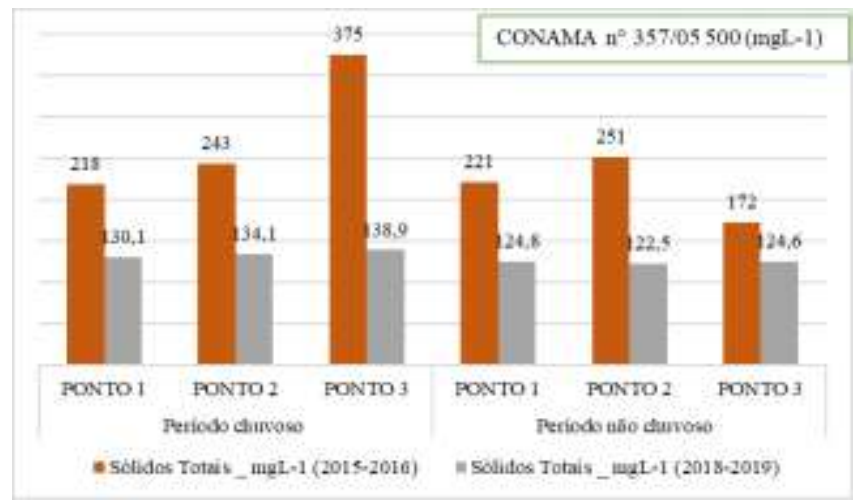

(b) Sólidos Totais

(c) Material Particulado em Suspensão

Fonte: Autores (2021).

\subsection{Variáveis Biológicas}

Franco (2003) completa, afirmando que os coliformes estão presentes em grandes quantidades nas fezes do ser humano e dos animais de sangue quente. A Figura 9 mostra as concentrações de Coliformes Totais e Termotolerantes presente no Riacho do Cacau.

A Resolução CONAMA no 357/2005 determina que a classe 2 seja um corpo hídrico destinado ao abastecimento humano, apresenta limite máximo de coliformes termotolerantes de $1.000 \mathrm{NMP}$ por $100 \mathrm{Ml}$. Com base nesse valor determina que a classe 2 pela resolução CONAMA n 357/2005, nota-se na Figura 9, que apenas o ponto 2 no período não chuvoso está fora do padrão preconizado pela resolução tanto para coliformes totais quanto para coliformes termotolerantes. Esse comportamento deve estar relacionado com as condições do ponto de coleta, pois o ponto 2 está localizado em uma área com uma maior urbanização em relação aos demais pontos. Cetesb (2008), afirma que coliformes termotolerantes são indicadores de poluição por efluentes sanitários e em temperaturas elevadas ideais $\left(44,5^{\circ} \mathrm{C}\right)$ multiplicam-se com mais facilidade. 
Figura 9 - Valores de Coliformes em ambos os períodos do ano.

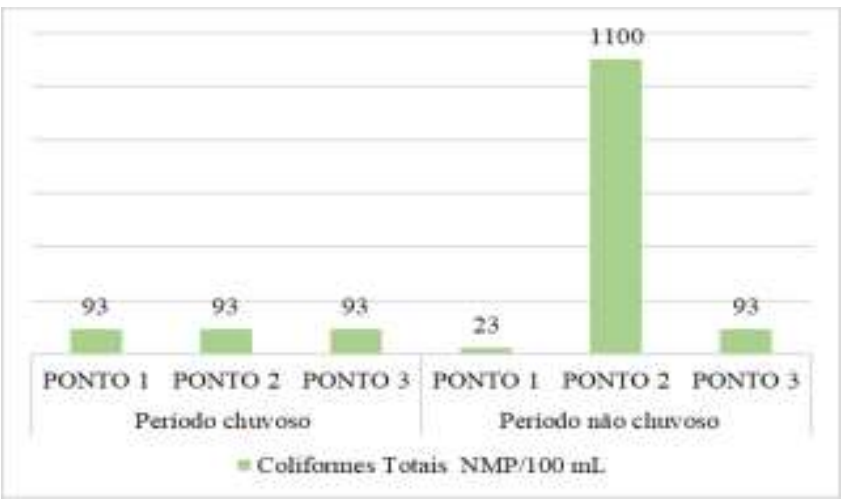

(a) Coliformes Totais

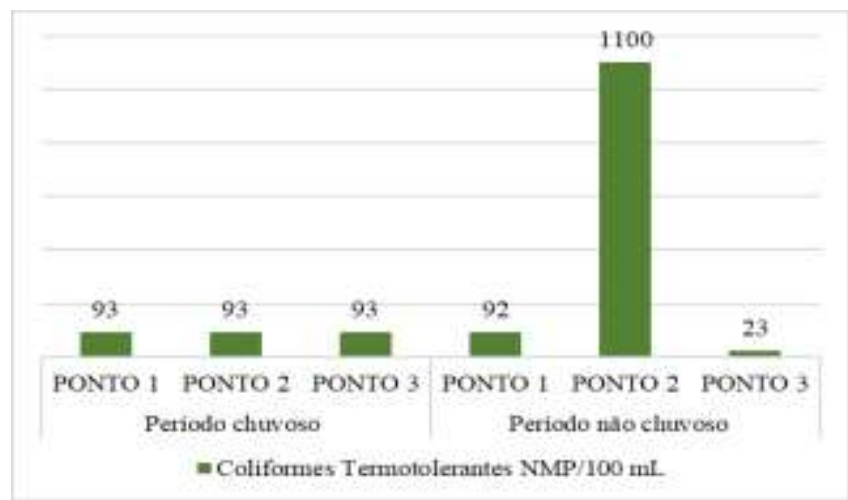

(b) Coliformes Termotolerantes

Fonte: Autores (2021).

\subsection{Análises de Correlação}

O uso do coeficiente de correlação de Pearson nas análises da intensidade e sua direção linear entre duas variáveis contínuas, pode se ter em termos de valor de $-1 \mathrm{a}+1$. Com isso quanto maior for o valor absoluto do coeficiente, mais forte é a relação entre as variáveis. Na correlação de Pearson, um valor absoluto de 1 indica uma relação linear perfeita. A correlação perto de 0 indica que não há relação linear entre as variáveis. O sinal de cada coeficiente indica a direção da relação, desta forma se ambas as variáveis tendem a aumentar ou diminuir em conjunto, o coeficiente é positivo, e a linha que representa a correlação inclina para cima. Se uma variável tende a aumentar à medida que os outras diminuem, o coeficiente é negativo, e a linha que representa a correlação inclina para baixo.

O primeiro valor corresponde ao valor de R de Pearson gerado, mostra o quão forte ou fraco foi a correlação. Além disso, os valores positivos ou negativos indicam se foi uma correlação positiva (significa que quando um aumenta o outro também aumenta) ou se foi uma correlação negativa (quando o aumento de um resulta na diminuição de outro). Em vermelho está o p estatístico cujo valor de alfa definido foi significativo, isto é, menor que 0,05 o que nos faz descartar a hipótese nula para esses resultados, a de que não há correlação significativa entre os parâmetros avaliados, sendo CTERMO, o Coliformes termotolerantes; CTOT os Coliformes totais; SST os Sólidos suspensos totais; FT o Fósforo total; NT o Nitrogênio total; e AL a Alcalinidade.

As análises de correlação que as variáveis apresentação correlação de Person de forte a muito forte, destacando-se as correlações a seguir: As correlações da condutividade com o pH e a Condutividade com Fósforo Total (Figura 10), por essa varável ser uma expressão numérica da capacidade de uma água conduzir a corrente elétrica, depende das concentrações iônicas e da temperatura e indica a quantidade de sais existentes na coluna d'água, e, portanto, representa uma medida indireta da concentração de poluentes. Em geral, níveis superiores a $100 \mu \mathrm{S} / \mathrm{cm}$ indicam ambientes impactados.

Por influir em diversos equilíbrios químicos que ocorrem naturalmente ou em processos unitários de tratamento de águas, o pH é um parâmetro importante em muitos estudos no campo do saneamento ambiental.

Desta forma, as restrições de faixas de $\mathrm{pH}$ são estabelecidas para as diversas classes de águas naturais, tanto de acordo com a legislação federal, quanto pela legislação do Estado de São Paulo. Os critérios de proteção à vida aquática fixam o pH entre 6 e 9 . 
Figura 10 - Correlação da Condutividade Elétrica com outras Variáveis de Qualidade da água.

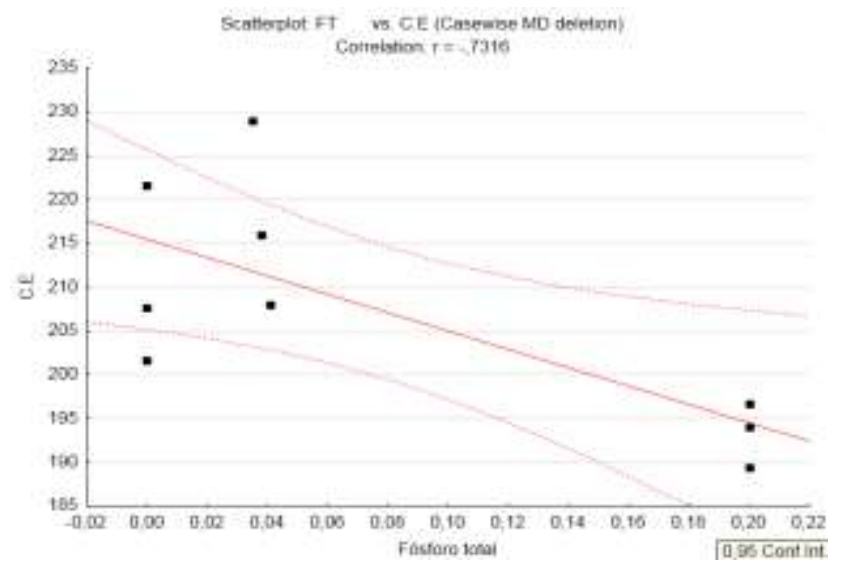

(a) C.E e Fósforo Total

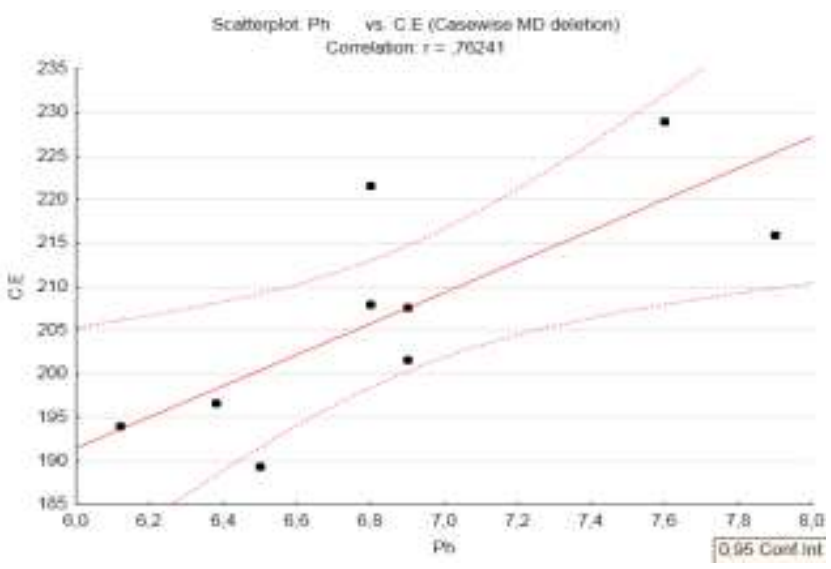

(b) C.E e pH

Fonte: Autores (2021).

$\mathrm{O}$ fósforo aparece em águas naturais devido principalmente às descargas de esgotos sanitários. Nestes, os detergentes superfosfatados empregados em larga escala domesticamente constituem a principal fonte, além da própria matéria fecal, que é rica em proteínas. Assim como o nitrogênio, o fósforo constitui-se em um dos principais nutrientes para os processos biológicos, ou seja, é um dos chamados macro-nutrientes, por ser exigido também em grandes quantidades pelas células, a forte correlação entre Nitrogênio e fósforo pode ser observada na Figura 11.

Houve forte correlação entre a diminuição da turbidez e o aumento do oxigênio dissolvido na água, isto pode ser demostrado pelo coeficiente de correlação $r$-0,7037, que mostra uma forte correlação entre as variáveis (Figura 12), assim como para o Nitrogênio Total e Fósforo Total.

Figura 11 - Correlação do Fósforo Total (P) com Nitrogênio Total.

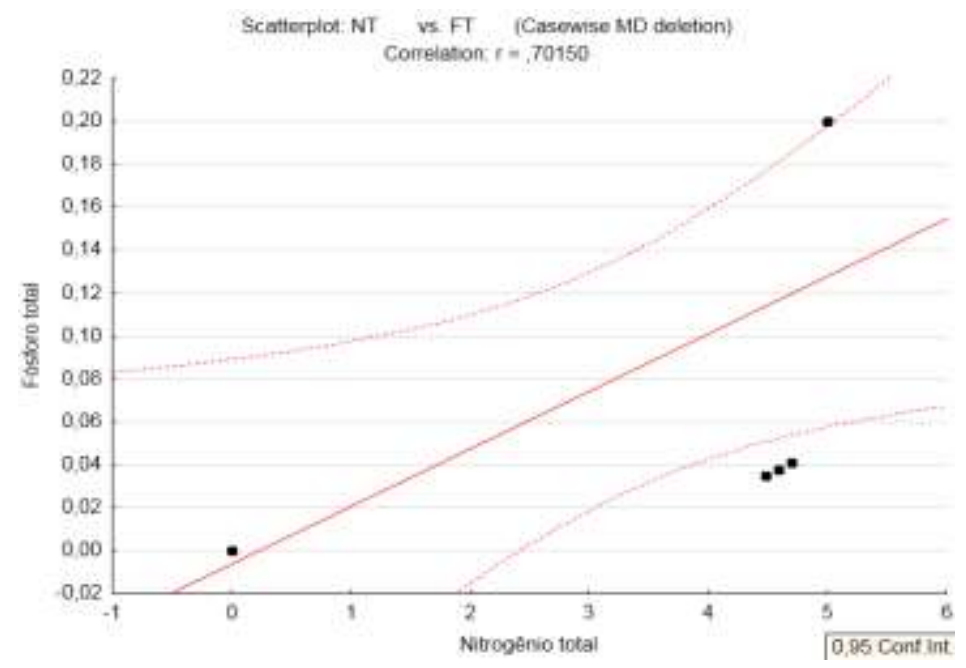

Fonte: Autores (2021). 
Research, Society and Development, v. 10, n. 2, e45510212631, 2021

(CC BY 4.0) | ISSN 2525-3409 | DOI: http://dx.doi.org/10.33448/rsd-v10i2.12631

Figura 12 - Correlação da Turbidez com outras variáveis de qualidade da água.

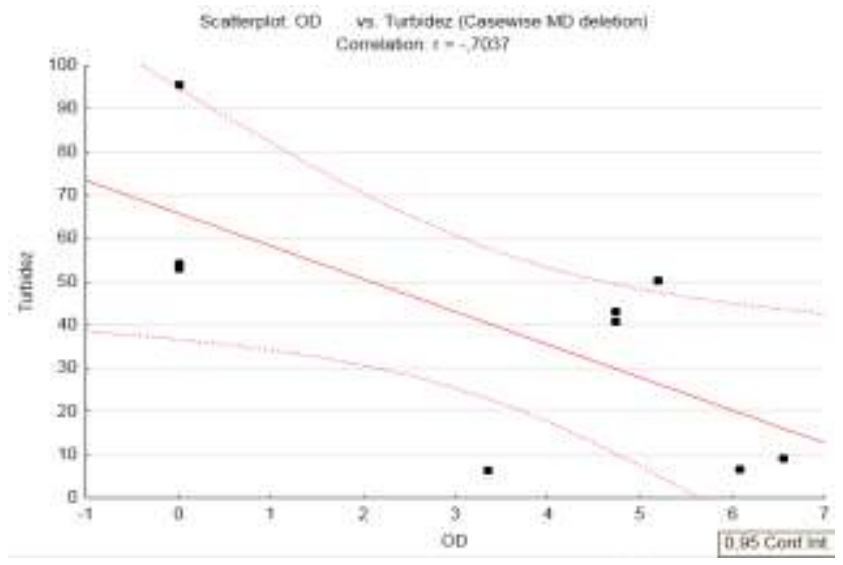

(a) Turbidez e Oxigênio dissolvido

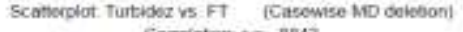

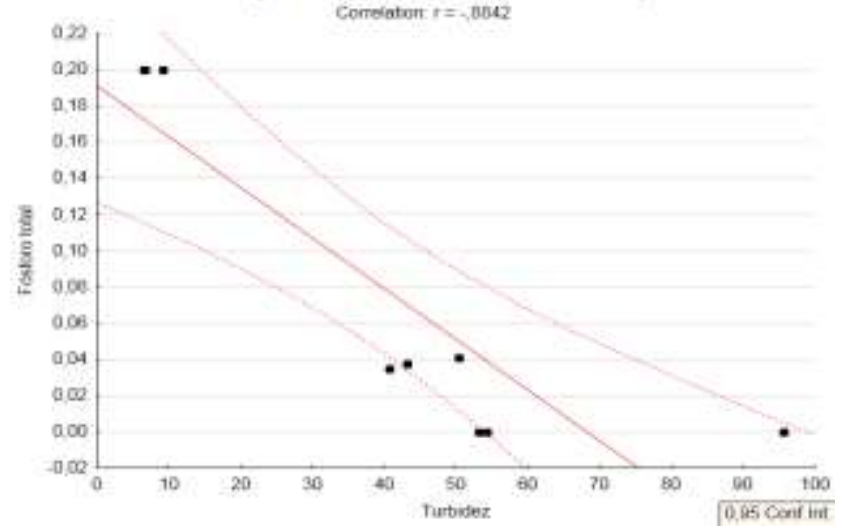

(c) Turbidez e Fósforo Total (P)

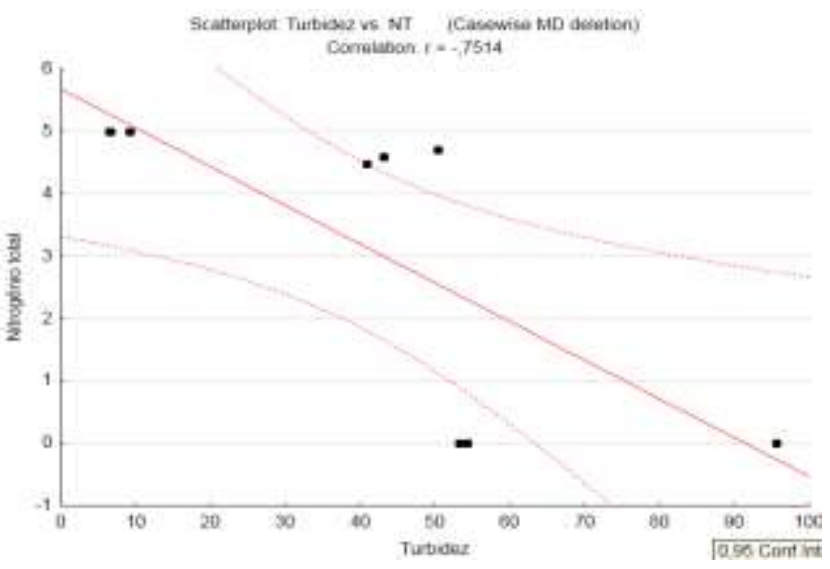

(b) Turbidez e Nitrogênio Total

Fonte: Autores (2021).

O teor de oxigênio dissolvido na água é inversamente proporcional a concentração de sólidos totais, isto pode ser observado na (Figura 13a), em que existe um forte correlação negativa entre o teor de oxigênio e a concenrtarção de sólidos. Assim, como observado uma correlação muito forte entre o teor de oxigênio e a concentração de cloreto na água (Figura 13b). Já acidez e presença de nitrogênio na água houve um forte correlação positiva de Pearson, com valores de r 0,943 e 0,947, respectivamente (Figura 13c e 13d). 
Figura 13 - Correlação do Oxigênio Dissolvido com outras Variáveis de Qualidade da Água.

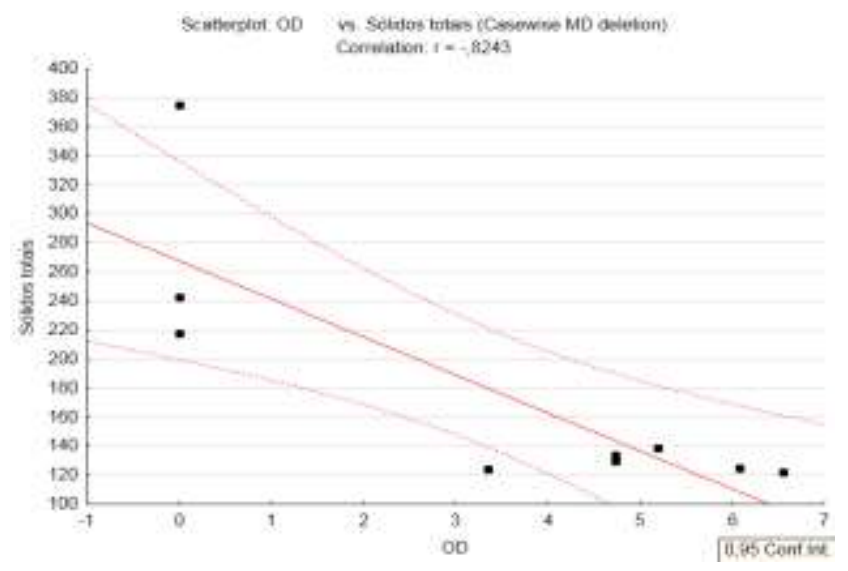

a) OD e Sólidos Totais

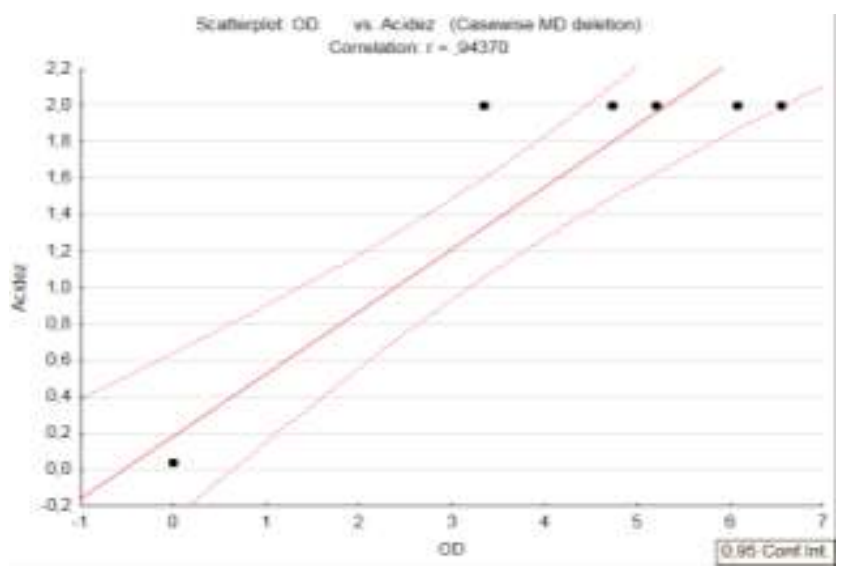

c) OD e Acidez

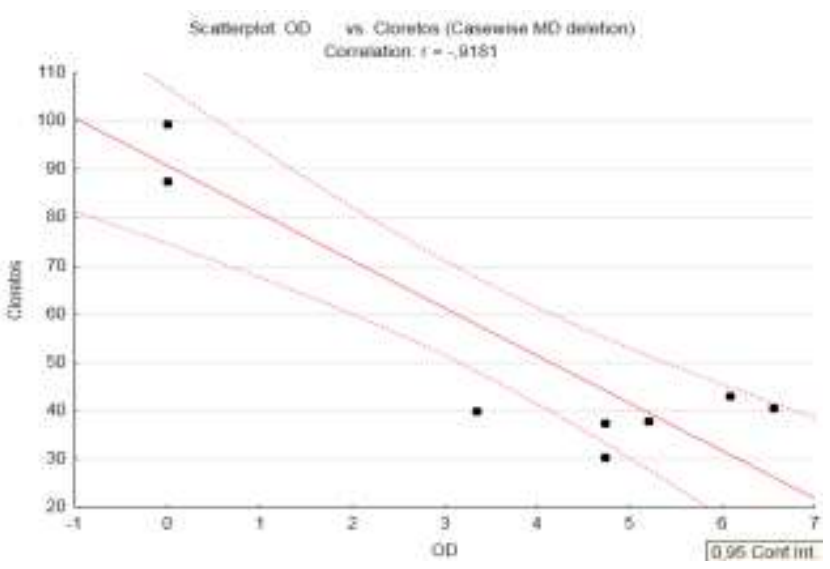

b) $\mathrm{OD}$ e Cloretos

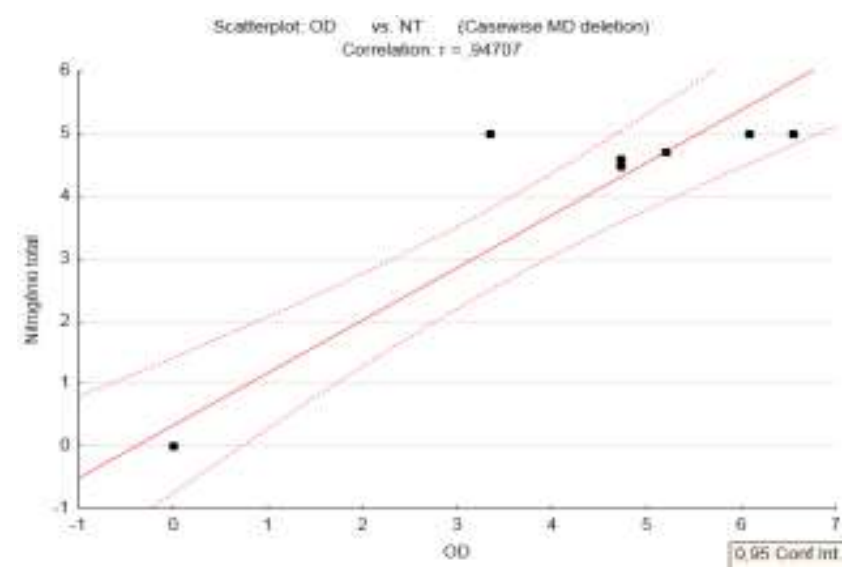

d) OD e Nitrogênio Total

Fonte: Autores (2021).

\subsection{Indicador de Qualidade da Água - IQA}

O Riacho Cacau obteve índices de qualidade de água variado de bom para excelente nos anos 2015-2016 quando comparados com os valores 2018-2019 (Tabela 2), em que 50\% das amostras obtiveram IQA Bom, 25\% IQA Excelente e 25\% Agradável.

Tabela 2 - Classificação do IQAb calculado segundo de Báscaran.

\begin{tabular}{ccccc}
\hline IQAb & \multicolumn{2}{c}{ 2015-2016 } & \multicolumn{2}{c}{ 2018-2019 } \\
\hline Período & Chuvoso & Não Chuvoso & Chuvoso & Não Chuvoso \\
\hline Ponto 1 & Excelente & Bom & Bom & Agradável \\
\hline Ponto 2 & Excelente & Bom & Bom & Agradável \\
\hline
\end{tabular}

Fonte: Autores (2021).

Nota-se uma diminuição na qualidade da água do riacho Cacau no decorrer dos anos, esse comportamento deve está diretamente ligado as mudanças causadas pelo crescimento imobiliário influenciado de forma direta a diminuição nos índices de qualidade de água, portanto causado uma maior contaminação por meio de maiores cargas de poluentes e contaminantes presentes nos efluentes domésticos e sanitários. Pode-se observar na Figura 14, que houve uma diminuição do IQA de 2015 para 2019, tanto no período chuvoso quanto no não chuvoso. 
Figura 14 - Valores de IQA.

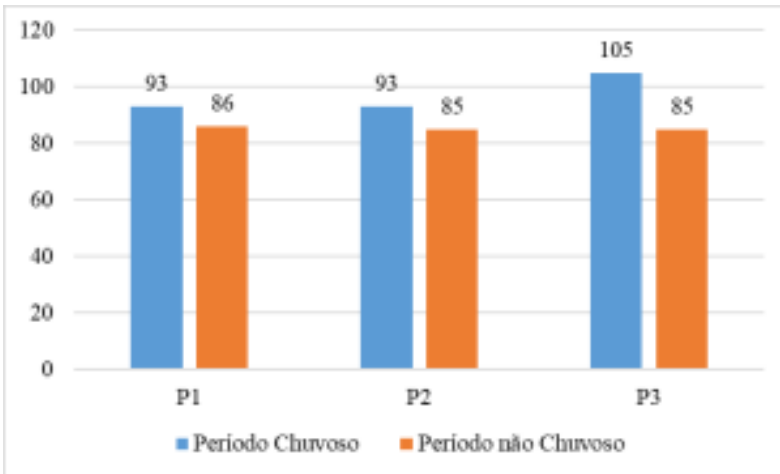

(a) IQAb 2015-2016

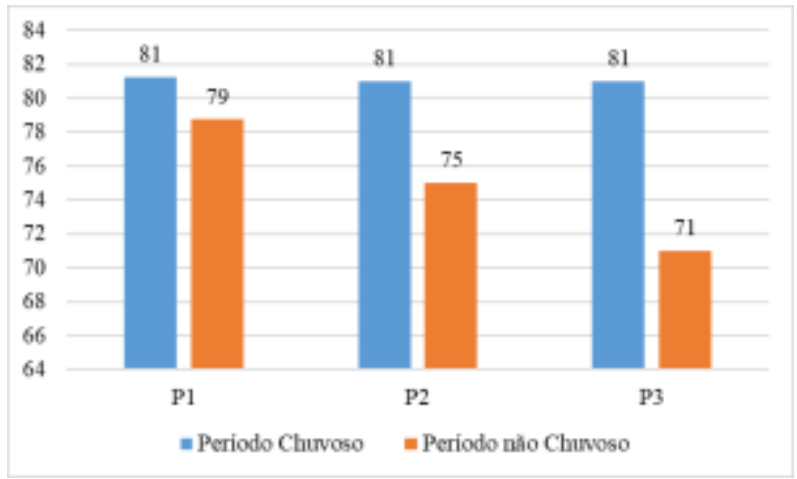

(b) IQAb 2018-2019

Fonte: Autores (2021).

\section{Conclusão}

As variações observadas para as variáveis físico-químicas ao longo do percurso amostrado indicam haver alterações na qualidade da água e essas alterações ocorrem em virtude de ações antrópicas tais como: os despejos de resíduos domésticos e sanitários líquidos, deflúvio superficiais urbanos, assoreamento, disposição inadequada de resíduos sólido e erosão do solo.

Os resultados obtidos demonstram uma forte existência de fontes pontuais e não pontuais causados pelo crescimento imobiliário ao logo dos anos na alteração nos valores de índice de qualidade da água. Acredita-se que uma campanha de conscientização de disposição adequada de resíduos sólidos aliada a uma readequação das instalações de esgoto e galerias pluviais e fluviais e tratamento desses efluentes, poder resolver o problema, de degradação do riacho Cacau. Nota-se então que a classificação de bom a agradável nos períodos estudados torna-se como aceitável porem não podemos descartar uma possível ausência de degradação hídrica.

\section{Referências}

Abreu, C. H. M. \& Cunha, A. C. (2015). Qualidade da Água em Ecossistemas Aquáticos Tropicais Sob Impactos Ambientais no Baixo Rio Jari-AP: Revisão Descritiva. Biota Amazônia, 5(2), 119-131.

Braga, B, Hespanhol, B., Conejo, J. G. L., Barros, M. T. L., Spencer, M., Porto, M., Nucci, N., Juliano, N. \& Eiger, S (2005). Introdução à Engenharia Ambiental: O desafio do desenvolvimento sustentável. São Paulo: Prentice Hall.

Brasil. Ministério do Meio Ambiente, Conselho Nacional do Meio Ambiente CONAMA - Resolução N³57, de 17 de março de 2005 . Brasília: Ministério do Meio Ambiente, 2005a.

CETESB - Companhia Ambiental do Estado de São Paulo, Secretaria do Meio Ambiente. Variáveis de qualidade das águas. <www.cetesb.sp.gov.br>.

CETESB - Companhia De Tecnologia De Saneamento AMBIENTAL -1988.

CETESB - Companhia De Tecnologia E Saneamento Ambiental. Determinação de fósforo em água: método do ácido ascórbico. Norma Técnica L5.128. São Paulo: CETESB, 1978.

CETESB, Companhia Ambiental do Estado de São Paulo. Relatório de Qualidade das Águas Interiores do Estado de São Paulo - Apêndice A - Significado ambiental e sanitário das variáveis de qualidade das águas e dos sedimentos e metodologias analíticas e de amostragem. 2008.

CONAMA - Conselho Nacional do Meio Ambiente. Resolução n 357/05. Estabelece a classificação das águas doces, salobras e salinas do Território Nacional. Brasília, SEMA, 2005.

Coradi, P. C., Fia, R. \& Pereira-Ramirez, O. (2009). Avaliação da qualidade da água superficial dos cursos de água do município de Pelotas-RS, Brasil. Revista Ambiente é Água, 4(2), 46-56.

Figueiredo Filho, D. B.\& Silva Júnior, J. A. (2009). Desvendando os Mistérios do Coeficiente de Correlação de Pearson. Revista Política Hoje, 18 (1), 2.

Fiorucci, A. R., \& Benedetti Filho, E. (2005). A importância do oxigênio dissolvido em ecossistemas aquáticos. Química Nova na Escola. 22, 10-16. 
Research, Society and Development, v. 10, n. 2, e45510212631, 2021

(CC BY 4.0) | ISSN 2525-3409 | DOI: http://dx.doi.org/10.33448/rsd-v10i2.12631

Franco, B. D. M. (2003). Microbiologia dos Alimentos. São Paulo: Atheneu.

Gertel, P., Tauk-Tornisielo, S. M., \& Malagutto, E. N. (2003). Qualidade das águas dos córregos São Joaquim e ribeirão Claro, bacia do rio Corumbataí-SP, Brasil. Holos Environment, 3(2), 103-119.

Jordão, C. P., Silva, A. C., Pereira, J. L., \& Brune, W. (1999) Contaminação por cromo de águas superficiais proveniente de curtumes em Minas Gerais. Química Nova. 22(1), 47-52.

Libânio, M. (2005). Fundamentos de qualidade e tratamento de água. Ca.

Macêdo, J. A. B. (2001). Métodos Laboratoriais de Análise-Físico-Químicas \& Microbiológico ÁGUAS \& ÁGUAS. Juiz de Fora: Jorge Macedo, 300 p.

Paláez-Rodriguez, M., Peret, A., Mtsumura-Tundis, T., \& Rocha, O. (2002). Análise da qualidade da água e aplicação do índice de proteção da vida aquática (IVA) em duas sub-bacias da bacia hidrográfica do rio Jacré-Guaçu. In: ESPÍNDOLA, E. L. G.

Poleto, C. (2014). Bacias Hidrográficas e Recursos Hídricos. Interciência. 272 p.

Rizzi, N. E. (2001). Índices de qualidade de água. Sanare, 15(15), 11-20.

Sodré, F. F., Patricio, G., Zamora, P., \& Grassi, M. T. (2004). Digestão fotoquímica assistida por microondas, de águas naturais aplicação em estudos de partição e especiação de cobre. Química Nova, 27(5), 695-700.

Santos, R. C. L., Lima, A. S., Cavalcanti, E. B., Melo, C. M., \& Marques, M. N. (2018). Aplicação de índices para avaliação da qualidade da água da Bacia Costeira do Sapucaia em Sergipe. Engenharia Sanitária e Ambiental, 23(1), 33-46.

Silva, G. S., \& Jardim, W. F. (2007). Aplicação do método da carga máxima total diária (CMTD) para a amônia no Rio Atibaia, região de Campinas/Paulínia, SP. Engenharia Sanitária e Ambiental, 12(2), 160-168.

Sperling, M. V. (2005). Introdução à qualidade das águas e ao tratamento de esgotos. $3^{\text {a }}$ Edição. Editora da Universidade Federal de Minas Gerais - UFMG Belo Horizonte.

Vieira, A. F. C., D. D., Dal Zotto,C. S. M, Fraporti, L., Malaguez, E. G., \& Hoch, G. C. (2016). Metodologias para determinação de Nitrogênio.

Tundisi, J. G., \& Tundisi, T. M. (2008). Limnologia. São Paulo: Oficina de Textos, 631p. 